\author{
結晶セルロース及びポリエチレングリコールを用いた \\ 遅延放出型アミノフィリン錠の調製と評価 ${ }^{1)}$ \\ 渡辺善照, ${ }^{*}$ 向井 麦, 河村健一, 石川達也 \\ 並木路広, 宇都口直樹, 藤井まき子
}

\title{
Preparation and Evaluation of Press-coated Aminophylline Tablet Using Crystalline Cellulose and Polyethylene Glycol in the Outer Shell for Timed-Release Dosage Forms ${ }^{1)}$
}

\author{
Yoshiteru Watanabe, ${ }^{*}$ Baku MUKaI, Ken-ichi Kawamura, Tatsuya IshiKawa, \\ Michihiro NAMIKI, Naoki UtOGUCHI, and Makiko FUJII \\ Department of Pharmaceutics and Biopharmaceutics, Showa Pharmaceutical University, \\ 3-3165, Higashi-Tamagawagakuen, Machida, Tokyo 194-8543, Japan
}

(Received July 9, 2001; Accepted November 7, 2001)

\begin{abstract}
In an attempt to achieve chronopharmacotherapy for asthma, press-coated tablets (250 $\mathrm{mg})$, which contained aminophylline in the core tablet in the form of low-substituted hydroxypropylcellulose (L-HPC) and coated with crystalline cellulose $(\mathrm{PH}-102)$ and polyethylene glycol (PEG) at various molecular weights and mixing ratios in the amounts of PH-102 and PEG as the outer shell (press-coating material), were prepared (chronopharmaceutics). Their applicability as timed-release (delayed-release) tablets with a lag time of disintegration and a subsequent rapid drug release phase was investigated. Various types of press-coated tablets were prepared using a tableting machine, and their aminophylline dissolution profiles were evaluated by the JP paddle method. Tablets with the timed-release characteristic could be prepared, and the lag time of disintegration was prolonged as the molecular weight and the amount of PEG, for example PEG 500000, in the outer shell were increased. The lag time of disintegration could be controlled by the abovementioned method, however, the $\mathrm{pH}$ of the medium had no effect on disintegration of the tablet and dissolution behavior of theophylline. The press-coated tablet (core tablet: aminophylline $50 \mathrm{mg}$, L-HPC and PEG 6000; outer shell: PH$102: \mathrm{PEG}=8: 2200 \mathrm{mg}$ ) with the timed-release characteristic was administered orally to rabbits for an in vivo test. Theophylline was first detected in plasma more than $2 \mathrm{~h}$ after administration; thus, this tablet showed a timed-release characteristic in the gastrointestinal tract. The time $\left(t_{\max }\right)$ required to reach the maximum plasma theophylline concentration $\left(C_{\max }\right)$ observed after administration of the press-coated tablet was significantly $(p<0.05)$ delayed compared with that observed after administration of aminophylline solution in the control experiment. However, there was no difference in $C_{\max }$ and area under the plasma theophylline concentration-time curve $\left(A U C_{0 \rightarrow 24}\right)$ between the press-coated tablet and aminophylline solution. These results suggest that the press-coated aminophylline tablet (with the timedrelease characteristic) offers a promising forms of theophylline chronotherapy for asthma.
\end{abstract}

Key words - timed-release preparation; press-coated aminophylline tablet; delayed-release profile; chronopharmacotherapy; chronopharmaceutics

\section{緒言}

近年, 時間薬理学 (chronopharmacology) の発 展に伴い薬物療法の研究において「時間」という要 因を考慮することが重要であると考えられてきてい る. ${ }^{2)}$ 人体の生理機能には周期的変動を示すものが 多い. 例えば 1 日を周期とする日周変化に応じて最

昭和薬科大学薬剤学研究室

e-mail:watanabe@ac.shoyaku.ac.jp
適な治療効果を与え，その有効性及び安全性を高め ようとする試みがあり，それは時間治療（chronotherapeutics）と呼ばれている.3)時間を考慮に入れ た薬物治療に対応する製剤の研究（時間製剤学, chronopharmaceutics)，例えば各種の放出制御製剂 技術4)重要である.

内服数時間後に効果の発現を期待したい場合，例 えば就眠数時間経過後（深夜から早朝）に発症しや すい病態に対しては，通常の製剤を就寝時に投与す 
ることでは対応できないことがある。この様な場 合，服用してから数時間後に薬物の放出を可能とす る遅延放出型（delayed-release）製剤が有用である と考えられる。5)この様な放出挙動を示す製剤に は，一般的に消化管内 $\mathrm{pH}$ の変化に依存する腸溶性 製剂がよく知られている。これらとは異なり $\mathrm{pH}$ に 依存しないシステムについては，大腸での環境で薬 物を放出する機構を備えたいわゆる大腸送達を目的 とした製剤と，消化管内の環境の違いによらず投与 後に消化管内の水分に接した時に製剂から薬物放出 が始まる機構（放出開始時間制御）を付与した遅延 放出型製剤（delayed-release preparations）などが ある．時間による制御が可能な遅延放出型製剂とし て，これまで浸透ポンプタイプ, ${ }^{6)}$ 栓離脱タイプ (Pulsincap) ${ }^{7)}$ などが研究されている．著者らは，特 殊装置によらず汎用される錠剂機で製造できる方法 として圧縮成形法を用い，有核錠（press-coated tablet）による検討を行った。本有核錠は，薬物を 含む核錠を非崩壊性の外層で被うことで核錠に水が 浸透するまで薬物の放出が起こらないように調製し たものである

本研究では, 就眠数時間後に発症しやすい病態の 例として，早朝に起こりやすいことが生体リズムと の関係から知られている喘息発作に着目した。. ${ }^{8,9)} こ$ の疾病への適用に遅延放出型製剤が有効と思われ る．著者らは，気管支喘息の治療薬であるアミノフ イリンを用い，遅延放出型錠の調製と評価を行った.

\section{実 験 の 部}

\section{1. 試料 アミノフィリン (ネオフィリン®} エーザイ)，低置換度ヒドロキシプロピルセルロー ス（L-HPC, LH-11 ${ }^{\circledR}$ ，信越化学)，結晶セルロー ス (PH-102, Avicel ${ }^{\circledR} \mathrm{PH}-102$ (粒子径, $\left.<75 \mu \mathrm{m}\right)$, 旭化成), ポリエチレングリコール (PEG, 分子量 $6000,50000,500000$ ，及び 2000000 （粒子径， 150 $-300 \mu \mathrm{m})$, 和光純薬) を用いた.

2. 有核錠調製法 ${ }^{10,11)}$ 核錠はアミノフィリン と L-HPC をプラスチック瓶に入れ 3 分間振とうし 混合したものを試料とし，これを両圧式粉末錠剤機 （N-20E 型，岡田精工）を用いて圧縮成形した（直 径 $5 \mathrm{~mm}$ ，重量 $50 \mathrm{mg}$ ). 次に外層成分として, $\mathrm{PH}$ -102 と PEG とを種々の割合（9：1-6：4）でプラ スチック瓶内で振とう混合した試料（Table 1）を
Table 1. Formulation of Tablet Using Dissolution Test

\begin{tabular}{lc}
\hline \hline Core tablet & \\
Aminophylline & $10 \mathrm{mg}$ \\
L-HPC & $40 \mathrm{mg}$ \\
Diameter & $5 \mathrm{~mm}$ \\
Compression force & $12.5 \mathrm{kN}$ \\
\hline Press-coated tablet \\
Core tablet \\
Outer shell ( PH-102 PEG $)$ \\
Diameter \\
Compression force & $50 \mathrm{mg}$ \\
& $200 \mathrm{mg}$ \\
& $20 \mathrm{~mm}$ \\
\hline
\end{tabular}

圧縮成形して有核錠（直径 $8 \mathrm{~mm}$, 重量 $250 \mathrm{mg}$ ） とした。

3. 溶出試験 第 13 改正日本薬局方溶出試験 法パドル法に準じて行った。なお，目視による核錠 の膨潤と外層の破裂状態の観察及び容器への付着を 防止するために，シンカーは用いずに網を底に沈め てその上に錠剤を落として試験した。一定時間ごと に試験液の吸光度を測定し，溶出率一時間曲線を調 ベた。試験条件：試験機, NTR-VS 型（富山産 業）; 試験液，精製水，第 13 改正日本薬局方崩壊試 験法第 1 液及び第 2 液，各 $900 \mathrm{ml}\left(37 \pm 1{ }^{\circ} \mathrm{C}\right)$; パ ドル回転数, $100 \mathrm{rpm}$; 定量法, 吸光度法（測定波 長， $272 \mathrm{~nm})$ 。試験開始後，製剤からの溶出が始ま るまでの時間を溶出遅延時間 (lag time)，及び溶 出が始まってから完了するまでの時間を溶出期間 (duration) とした

4. 動物試験実験動物は首枷法 ${ }^{12)}$ を用いて食 糞を防止した。実験前一昼夜，水のみを自由に与え て絶食させた日本白色種ウサギ（体重 $2.7-3.3 \mathrm{~kg}$ ） を用いた。ウサギにアミノフィリン $50 \mathrm{mg}$ を含む 液剂 $(3 \mathrm{ml})$, 核錠又は有核錠を各 1 錠経口投与後, 一定時間毎に耳静脈より血液 $2 \mathrm{ml}$ を採取し，血漿 中のテオフィリン濃度を Franconi ら ${ }^{13)}$ の HPLC 法 に準じて測定した。測定条件：装置, Model 510 （Waters, USA）；カラム，Wakosil-II 5C18, 4.6 $\mathrm{mm} \times 150 \mathrm{~mm}$; 移動相， $0.01 \mathrm{M}$ 酢酸ナトリウム緩 衝液（pH 4.0）：アセトニトリル $=96 ： 4$ （流速, $1.0 \mathrm{ml} / \mathrm{min}$ ）; 内部標準物質，7-[2-hydroxyethyl]theophylline ( $4 \mu \mathrm{g} / \mathrm{ml}$ メ夕ノール溶液)；検出器, 紫外可視分光光度計検出器 (SPD-6A, 島津製作 所，測定波長， $273 \mathrm{~nm}$ ). 


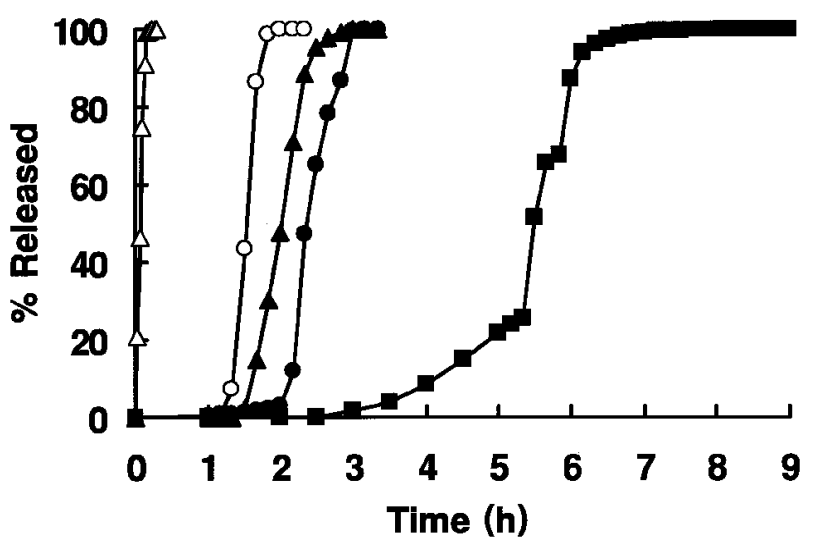

Fig. 1. Dissolution Profiles of Theophylline from Core Tablet or Press-coated Tablet Prepared Using PH-102 in Combination with Various PEGs (Weight Ratio, 8:2) for Press-coated Material (Outer Shell)

Dissolution test: JPB Paddle method, $100 \mathrm{rpm}$. Core tablet: $\triangle$ and Press-coated tablet: $\bigcirc: 6 \times 10^{3}, \mathbf{\Delta}: 50 \times 10^{3}, \mathbf{O}: 500 \times 10^{3}, \mathbf{\square}: 2 \times 10^{6}$ (molecule weight of PEG in outer shell of press-coated tablet). Each value represents the mean of six experiments.

\section{5. 薬動学的解析 投与後に得られた各血漿中} テオフィリン濃度一時間曲線より, 最高血漿中濃度 $\left(C_{\max }\right)$ 及び最高血漿中濃度到達時間 $\left(t_{\max }\right)$ を求 めた。血漿中テオフィリン濃度一時間曲線下面積 $\left(A U C_{0 \rightarrow 24}\right)$ は，台形則に従って投与後 24 時間ま での測定值を用いて算出した。統計学的評価は, one-way ANOVA 及び Dunnett 法により行い, $p<$ 0.05 の場合に有意差ありと判断した.

\section{結果及び考察}

1. 外層に用いる PEG の分子量を変えたときの 有核錠からのテオフィリン溶出挙動＼cjkstart有核錠から のテオフィリンの溶出に及ぼす外層に用いる PEG の分子量の影響を調べるために，PEG6000, 50000, 500000 ，及び 2000000 を用いて外層を成形した有核 錠からのテオフィリン溶出挙動を示す (Fig. 1).

核錠に比べて有核錠では外層に用いた PEG の分子 量が PEG6000 から 500000 まで大きくなると lag time の延長が認められた $(1 \rightarrow 2 \mathrm{~h})$. 溶出が開始し てから終了するまでの時間（duration）はいずれの 場合も約 40-60 min で，速やかであった。 PEG2000000 を用いると他のPEG と異なり lag time は約 $2.5 \mathrm{~h}$ で最も延長した。しかし， duration は約 $4 \mathrm{~h}$ かかることが明らかとなり，他の 3 製剤と 比べて溶出挙動が大きく相違し，遅延放出プロファ イルとして不適切と判断した。上記の結果から,

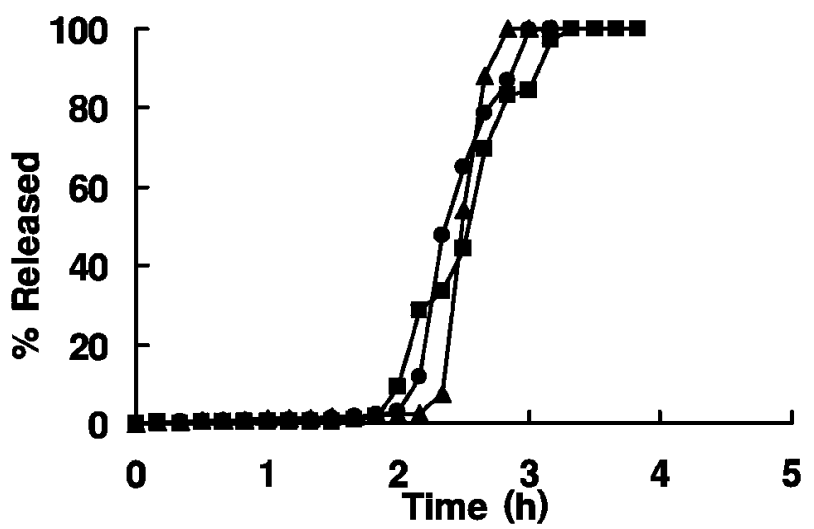

Fig. 2. Dissolution Profiles of Theophylline from Press-coated Tablet in Various Dissolution Medium

Dissolution medium: $\mathbf{O}$ : Purified water, $\boldsymbol{\Delta}$ : The first fluid for disintegration test $(\mathrm{pH} 1.2, \mathrm{JP13}), \mathbf{\mathbf { a }}$ : The second fluid for disintegration test $(\mathrm{pH}$ 6.8, JP13). Each value represents the mean of six experiments.

PEG500000 を以下の検討に用いた.

2. 溶出液の pH を変えたときの有核錠からのテ オフィリン溶出挙動 Figure 2 に精製水，日本薬 局方崩壊試験法第 1 液（ $\mathrm{pH}$ 1.2）及び第 2 液（ $\mathrm{pH}$ 6.8）を用いて溶出試験を行ったときのテオフィリ ン溶出挙動を示す．外層は， PH-102 $160 \mathrm{mg}$, PEG500000 $40 \mathrm{mg}$ としたものを用いた。いずれ の試験液中においても約 $2 \mathrm{~h}$ までテオフィリンの溶 出は全く観察されず (lag time, $2 \mathrm{~h}$ )，溶出挙動に $\mathrm{pH}$ の差は影響しないことが明らかとなった。した がつて, 服用後胃内での $\mathrm{pH}$ の変動・差（無酸症患 者など）が生じても，薬物の溶出は影響されにくい と考えられる。

3. 外層に用いる PH-102 と PEG500000 の重量 比を変えたときの有核錠からのテオフィリン溶出挙 動 Figure 3 に, 外層に用いる $\mathrm{PH}-102$ と PEG500000 の重量比を変えたときの有核錠からの テオフィリン溶出挙動を示す。上記で検討した $\mathrm{PH}$ -102 と PEG500000 との重量比 $8: 2$ に変えて $9: 1$, $7: 3$ 及び $6: 4$ としたものを用いた。重量比 $8: 2$ に比べ, PEG500000 の割合を減らしたとき，すな わち PH-102：PEG500000 が 9: 1 のとき lag time が短くなったが，PEG500000 の割合を増やす（7：

3，6:4）と lag time は延長した。しかし $7: 3$ と $6: 4$ とでは溶出挙動がほぼ同じであった.

遅延放出型製剤に関してはこれまで時間制御破裂 顆粒（time-controlled explosion system (TES) ), ${ }^{14)}$ ヒドロキシプロピルメチルセルロース（HPMC） 
層被膜 Chronotropic DDS, ${ }^{15)}$ ヒドロキシプロピル セルロース（HPC）を外層とした錠剤16)など種々 の製剂が報告されている．Ishino ら ${ }^{11)}$ は，薬物と力 ルメロースカルシウムからなる核錠の周りを硬化ヒ マシ油などで圧縮成形した錠剤を，Matsuo ら ${ }^{17)}$ 薬物を含む核錠の周りにヒドロキシエチルセルロー ス（HEC）を圧縮成形した錠剤を報告している. 機能的特徵として，前者は外層を透過した水分によ り核錠が膨潤し外層を破裂させる製剤であり，後者 は外層の HEC の粘度グレードの選択とセルロース 量の加減で放出開始時間を調節する製剂である．今 回著者らは，Ishino らの方法と異なり硬化ヒマシ油

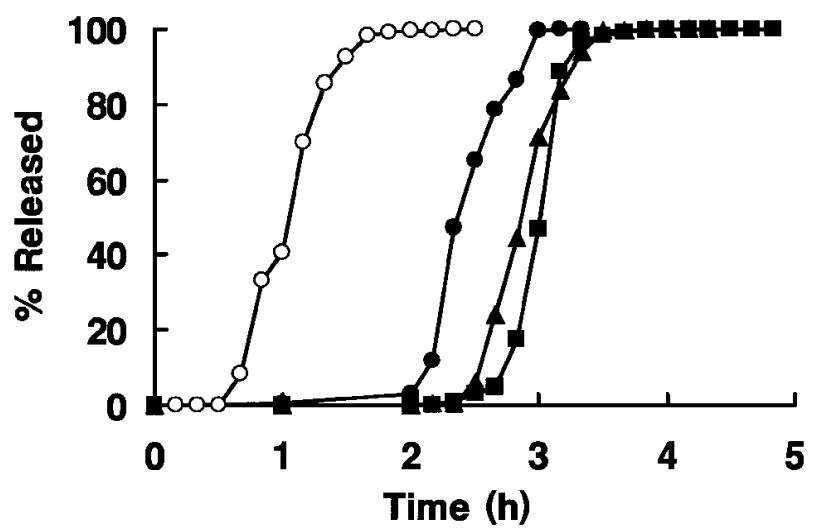

Fig. 3. Comparison of Theophylline Dissolution Profiles from Press-coated Tablet Using PH-102 and PEG $500 \times 10^{3}$ in Various Mixing Ratio in Weight

Mixing ratio of PH-102: PEG500 $\times 10^{3}: \bigcirc: 9: 1$, О: $8: 2, \mathbf{\Delta}: 7: 3$,

口: $6: 4$. Each value represents the mean of six experiments.
（油脂性）に代えて錠剤製造に汎用される PH-102 とPEG500000 を用いて外層破裂タイプの遅延放出 型アミノフィリン錠(有核錠)を新規に開発できた。 この有核錠の圧壊強度は $20 \mathrm{~kg}$ 以上（核錠のみは約 $4 \mathrm{~kg}$ ）で速やかな崩壊は生じない。また，有核錠表 面がゲル化して溶解することはない。したがって， 表面から浸透した水が PEG を徐々に溶解させ核錠 に到達すると推定される. Figure 4 に模式的に示す ように，時間経過後外層中を浸透した水が核錠に到 達すると速やかに核錠が膨潤して外層が破壊され， 錠剤全体が崩壊して薬物を放出するものと考えられ る.

Figures 1 及び 2 に示すように，今回調製した有 核錠からの薬物溶出は核錠に比べて明らかに遅延す ること，また溶出プロファイルは $\mathrm{pH}$ の差に影響さ れないことが見出された。 また，テオフィリン溶出 までの lag time は，外層に用いる PEG の分子量を 変えること，外層に用いる $\mathrm{PH}-102$ と PEG の重量 比を変えることで調節が可能であると考えられる。

4. アミノフィリン有核錠をウサギに経口投与後 の血漿中テオフィリン濃度＼cjkstart外層 $(200 \mathrm{mg}$ ) の PH-102 及び PEG500000 の重量比を $8: 2$ とした錠 剂をウサギに経口投与した。なお動物試験に用いる ために，核錠（直径 $5 \mathrm{~mm} ）$ はアミノフィリン 50 mg, L-HPC 20 mg, PEG6000（滑沢剂） 7 mg とし た。対照試験としてアミノフィリン $(50 \mathrm{mg})$ 水溶 液を投与した。なお，この錠剤（直径 $8 \mathrm{~mm}$ ）から

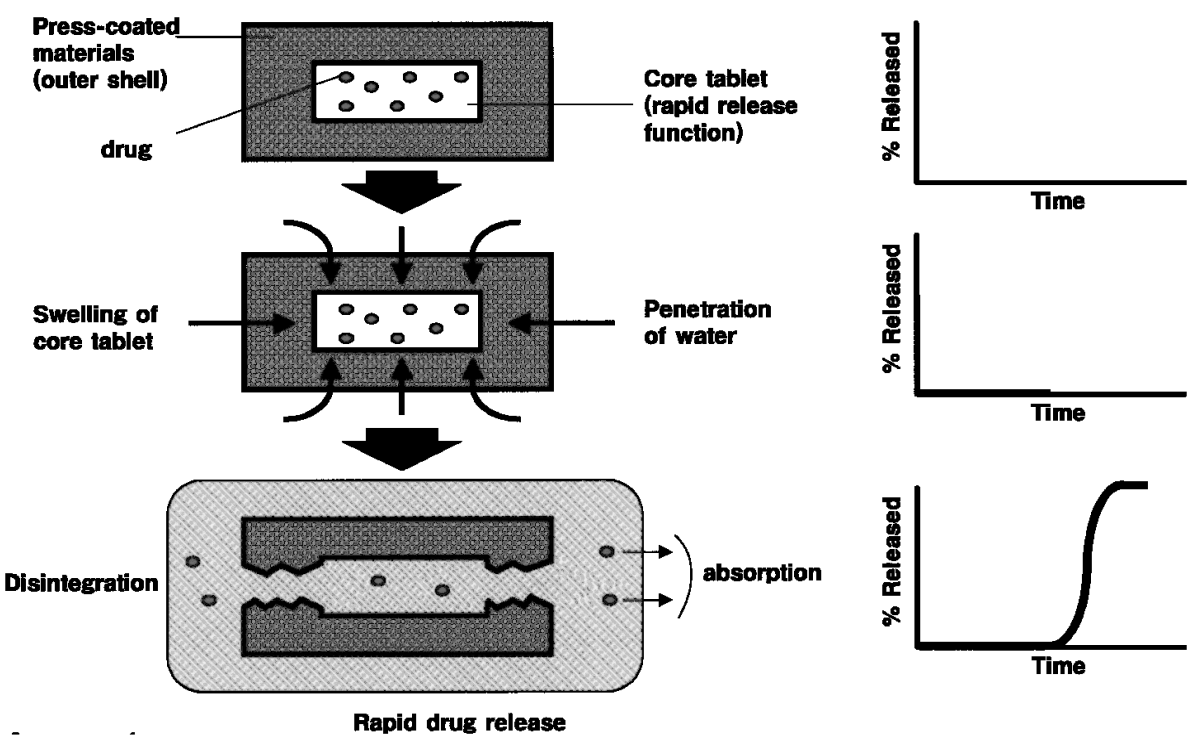

Fig. 4. Schematic Illustration of Drug Release Characteristics from Press-coated Tablet (Timed-release Tablet) 


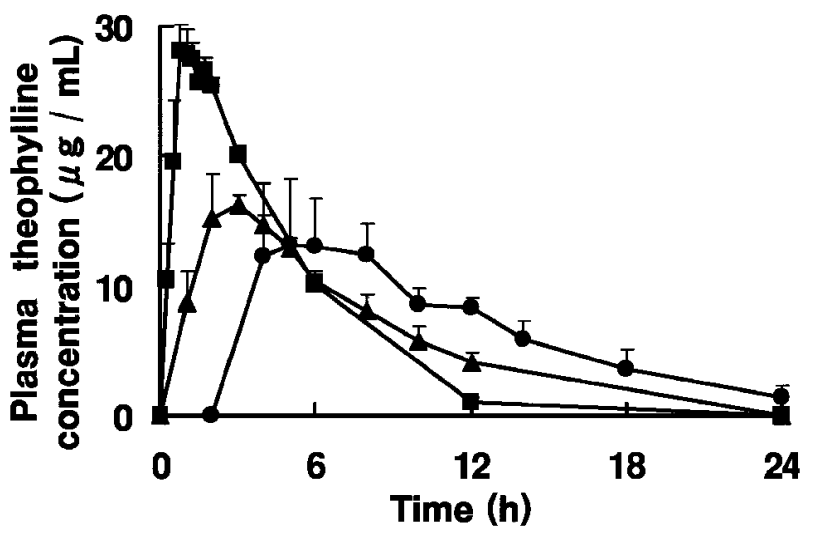

Fig. 5. Plasma Theophylline Concentration-time Curves in Rabbits Following Oral Administration of Aqueous Solution, Core Tablet or Press-coated Tablet Containing Aminophylline $(50 \mathrm{mg})$

Preparation: $\mathbf{n}$ : Aqueous solution, $\mathbf{A}$ : Core tablet, $\mathbf{0}$ : Press-coated tablet. Each point represents the mean \pm S.E. of three or four experiments.

のテオフィリン溶出は遅延放出プロファイルを示し た. Lag time は約 $1.5 \mathrm{~h}$ になったが，これはアミノ フィリン量が増加したため核錠の厚さが増し，外層 の厚さが小さくなったためと見られる. Figure 5 に ウサギに各種製剤投与後の血漿中テオフィリン濃度 一時間曲線を示す．液剤，核錠では投与直後から血 漿中にテオフィリンが認められたが，有核錠では 2 $\mathrm{h}$ までテオフィリンが血漿中に観察されずその後濃 度が上昇した。Table 2 に示すように，対照試験 (液剂投与) の $t_{\max }(1.3 \pm 0.3 \mathrm{~h})$ と比べて核錠での

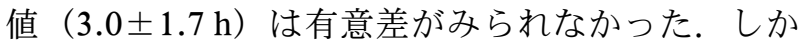
し，有核錠投与後は $t_{\max }$ が $8.5 \pm 1.9 \mathrm{~h}$ となり対照試 験の值に比べて，有意 $(p<0.05)$ に遅れた。しか し，有核錠における吸収開始時間からの最高血漿中 濃度到達時間（5.8 $\pm 1.4 \mathrm{~h} ）$ は対照製剂の值（1.3土

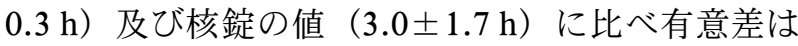
なかった。なお， 3 製剤間で投与後の $A U C_{0 \rightarrow 24}$ に ついては有意差はなかった．したがって，消化管内 においてもこの有核錠はテオフィリンの溶出開始を 遅らせる機能を発揮するものと考えられる。

睡眠中早朝の喘息治療については，コンチンシス テム採用のテオフィリン徐放性製剂（ユニフィル ${ }^{\circledR}$ ) などが上市されている，今回調製した有核錠は，経 口投与した場合，対照製剂（液剂）や核錠に比べて 明確に吸収の開始を遅延するが，吸収開始後の $C_{\max }, t_{\max }$ 及び $A U C_{0 \rightarrow 24}$ には核錠と差が見られない ことが明らかとなつた。錠剤製造に繁用される $\mathrm{PH}$
Table 2. Pharmacokinetic Parameters of Theophylline after Oral Administration of Aminophylline Preparations in Rabbits

\begin{tabular}{lccc}
\hline \hline & $\begin{array}{c}t_{\max } \\
(\mathrm{h})\end{array}$ & $\begin{array}{c}C_{\max } \\
\mu \mathrm{g} / \mathrm{ml})\end{array}$ & $\begin{array}{c}A U C_{0 \rightarrow 24} \\
(\mathrm{~h} \cdot \mu \mathrm{g} / \mathrm{ml})\end{array}$ \\
\hline Solution & $1.3 \pm 0.3$ & $29.0 \pm 1.6$ & $150.3 \pm 4.8$ \\
$\begin{array}{l}\text { Core tablet } \\
\begin{array}{l}\text { Press-coated } \\
\text { tablet }\end{array}\end{array}$ & $3.0 \pm 1.7$ & $17.6 \pm 1.6$ & $139.2 \pm 5.3$ \\
\hline
\end{tabular}

Each value represents the mean \pm S.E. of three and four experiments. Statistically significant differences: a) $p<0.05$ in press-coated tablet $v s$. solution.

-102 と PEG を用いて外層破裂タイプの遅延放出型 アミノフィリン錠（有核錠）を新規に調製できた.

\section{REFERENCES AND NOTE}

1) This study was presented at the 10th Annual Meeting of the Japanese Society of Hospital Pharmacy, Kyoto, October, 2000.

2) a) Takahashi R., Halberg F., Walker C. A. (eds.), Toward Chronopharmacology, Advances in Biosciences, Vol. 41, Pergamon Press, 1982; $b$ ) Reinberg A. E., Ann. Rev. Pharmacol. Toxicol., 32, 51-66 (1992).

3) Yoshiyama Y., Farumashia, 34, 573-578 (1998)

4) Kobayashi M., Pharm Tech Japan, 17, 89-103 (2001).

5) Nakano M., Igakunoayumi, 178, 441-444 (1996).

6) Nakano M., Gekkan Yakuji, 41, 1103-1106 (1999)

7) Makino K., Farumashia, 37, 382-384 (2001).

8) Barnes P. J., N. Engl. J. Med., 321, 15171527 (1989).

9) Uematsu T., Nakano M., Kosuge K., Kanamaru M., Nakashima M., Eur. J. Clin. Pharmacol., 44, 361-364 (1993).

10) Maekawa H., "Iyakuhinkaihatsukisokouza $X$ Seizaikougaku," Chijinshokan, Tokyo, 1971, pp. 218-224.

11) Ishino R, Yoshino H., Hirakawa Y., Noda K., Chem. Pharm. Bull., 40, 3036-3041 (1992).

12) Maeda T., Takenaka H., Yamahira Y., Noguchi T., Chem. Pharm. Bull., 27, 30663072 (1979).

13) Franconi L. C., Hawk G. L., Sandmann B. J., 
Haney W. G., Anal. Chem., 48, 372-375 (1976).

14) Hata T., Ueda S., Pham Tech Japan, 4, 14151422 (1988).

15) Gazzaniga A., Sangalli M. E., Giordano F., Eur. J. Pharm. Biopharm., 40, 246-250
(1994).

16) Fukui E., Uemura K., Kobayashi M., J. Controlled Rel., 68, 215-223 (2000).

17) Matsuo M., Nakamura C., Arimori K., Nakano M., Chem. Pharm. Bull., 43, 311-314 (1995). 